\title{
Spatial analysis of road crash frequency using Bayesian models with Integrated Nested Laplace Approximation (INLA)
}

\author{
Romi Satria ${ }^{a}$, Jonathan Aguero-Valverde ${ }^{b}$, and Maria Castro ${ }^{a}$ \\ a Departamento de Ingenieńa del Transporte, Territorio y Urbanismo, Universidad Politécnica de \\ Madrid, Madrid, Spain. \\ ${ }^{\text {b}}$ Programa de Investigación en Desarrollo Urbano Sostenible, Universidad de Costa Rica, San \\ José, Costa Rica
}

\begin{abstract}
Improving traffic safety is a priority of most transportation agencies around the world. As part of traffic safety management strategies, efforts have focused on developing more accurate crash-frequency models and on identifying contributing factors in order to implement better countermeasures to improve traffic safety. Over time, models have increased in complexity and computational time. Bayesian models using the MCMC method have been commonly used in traffic safety analyses because of their ability to deal with complex models. Recently, the INLA approach has appeared as an alternative to the MCMC method by significantly reducing the computing time. In this study, an INLA-CAR model is developed to assess crashes by severity at the segment level on a highway section in Banda Aceh, Indonesia and is compared with a Bayesian non-spatial model. Results of the DIC show the importance of including spatial correlation in the models. The coefficient estimates show that AADT is the most influential in both models and across all severity types; however, the coefficient estimates for land use and horizontal alignment vary across severity types. Finally, in order to assess some limitations of the DIC, three other goodness-of-fit measures are used to crossvalidate the results of the DIC.
\end{abstract}

\section{KEYWORDS}

Bayesian analysis; INLA; road crash; spatial correlation

\section{Introduction}

Road traffic crashes are a primary issue worldwide. Every year, several millions of users are injured or died on roads around the world. In fact, road traffic crashes are currently estimated to be the ninth leading cause of death across all age groups globally, and are predicted to become the seventh leading cause of death by 2030 (World Health Organization, 2015). The significant impacts these crashes represent for societies and economies have made reducing the number of crashes a major priority in most 
countries in the world. This goal requires a good understanding on how, why and where crashes occur. It also requires to correctly identify contributing factors to road traffic crashes in order to establish comprehensive and appropriate measures to prevent them.

Globally, the high number of road traffic crashes is driven by an escalating death toll on roads in emerging low and middle-income countries due to an increasing access to motorization associated with rapid economic growth (World Health Organization, 2015). Indonesia is no exception. This country, located in South East Asia, has seen consistently high rates of annual road traffic crashes. With a population of over 260 million inhabitants and a ratio of about one vehicle for every two persons, road safety is of primary concern for governmental agencies (World Health Organization, 2018). In 2018, WHO estimated the number of deaths on Indonesian roads to about 31,726 persons or 12.2 deaths per 100 thousand persons (World Health Organization, 2018).

Efforts to reduce the number of road traffic crashes in all continents have led to the development of a myriad of methodologies to analyze them. Yet, there is still an important gap in terms of data and information availability. Most of the research comes from US, Europe or Australia and lessons learnt there are often not applicable in the South East Asian context, nor in Indonesia.

Modern methodologies using a combination of geographic information systems and statistical models can be very effective to spot and map road traffic crashes as well as to identify contributing factors to these crashes. However, these more complex methodologies also require more data and computational resources than traditional methods, and often have long processing times. Bayesian inference is a widely used method to analyze road traffic crashes. With model complexity increasing, there has been a growing use of Monte Carlo techniques for sampling probability distributions using Markov chain (also known as Markov Chain Monte Carlo (MCMC) methods). Recently, the Integrated Nested Laplace Approximations (INLA) was developed as a faster alternative to MCMC methods. INLA has been shown to overcome some of the difficulties MCMC methods can encounter, notably in terms of convergence and computational time (Rue, Martino, \& Chopin, 2009), and to compute very accurate approximations of posterior distributions in a very short amount of time (Hue et al. 2013).

The objectives of this paper are to develop a crash frequency model at the roadway segment level on one of the main highways of the Aceh province in Indonesia, based on different severity level; and identify factors contributing to road crashes. Secondly, the paper also aims to contribute to expanding knowledge and understanding about the road traffic safety context in Indonesia. Understanding where crashes occur and what the 
contributing factors are is a first step for decision-makers to be able to take informed decisions and to put in place appropriate measures to improve safety on roads.

The methodology brings together two approaches, the Full Bayes approach with the Integrated Nested Laplace Approximation (INLA) approach. The use of INLA significantly reduces computational times and requires less iteration time to fit the model over MCMC, which is helpful as datasets become bigger and more complex (Rue et al., 2009). The INLA package for the $\mathrm{R}$ software was used in this study. The model developed in this study allows to predict the probability of a crash under certain road crash characteristics and identifies the main factors contributing to accidents based on different severity types. This model also provides a theoretical support for decision-makers to thoroughly analyze the main contributing factors of road crashes and establish a basis for improving safety performance.

The paper is organized in six sections. After the introduction, the second section reviews available literature on the use of conditional autoregressive models (CARs) and INLA in crash frequency. The methodology developed for this study is described in the third section. Section 4 presents the study area and section 5 analyses the results of the models and reviews the different goodness-of-fit measures. The last section summarizes the findings and makes suggestions for future work.

\section{Literature review}

Over the past decades, a large number of methodologies to analyze road traffic crashes have emerged and have furthered our understanding of factors contributing to these road crashes. Traditional methodologies were nonspatial and commonly using crash count data and other statistical methods. Poisson regression techniques, for example, have been commonly used for crash count data (Jovanis \& Chang, 1986; Miaou \& Lum, 1993). While these models are easy to estimate, they are unable to handle over- and underdispersion and can be negatively influenced by a low-sample mean.

The appearance of GIS and its increasing use in the field of road safety have been associated with the development of new methodologies taking into account the spatial element on road crashes. By considering the spatial dimension of crashes, spatial-statistical methodologies have allowed significant progress in understanding trends and patterns of road crashes, and in identifying areas of particularly high risk. Including spatial correlation in crash frequency models allows sites to estimate 'pool strength' from neighboring sites to improve model estimation (Aguero-Valverde \& Jovanis, 2008). This is particularly important with datasets presenting high random 
variability and small expected frequencies (Aguero-Valverde, 2011). As these models increased in complexity, they also became more data-heavy, more computationally demanding and more time consuming, therefore requesting the development of appropriate methods to be able to respond to these needs.

Alongside the increase in computational and simulation capabilities, Bayesian models have emerged as a more suitable alternative to classical models based on count data. Bayesian models use both prior and sample information and go a step beyond classical models in that they allow direct probability interpretations of the parameters given an observed set of data.

Among their strengths, Bayesian models are more flexible; they can handle data with low counts and account for spatial correlation (Boulieri, Liverani, de Hoogh, \& Blangiardo, 2017). There exists a wealth of literature of the use and contributions of Bayesian models in the field of traffic safety. For example, Mitra (2009) developed a methodology to identify hazardous road locations and highlighted the importance of spatial autocorrelation in GIS to detect clusters of fatal and injury crashes. The author also compared the results of the classical negative binomial model against those a Bayesian spatial statistical method; and showed that the latter provided in more precise estimations when modeling high crash concentration locations. Li, Zhu, and Sui (2007) used a Bayesian model coupled with GIS for posterior risk mapping to show road segments requiring safety improvement. They identified the spatial-temporal patterns of related potential crashes risks and established a ranking of the potentially high-risk segments for road crash.

Spatial methods have been used in numerous studies, especially Conditional autoregressive (CAR) models. These are a class of spatial models that have commonly been used for areal data. In CAR models, the spatial relationship is modeled through a spatial weight matrix. Furthermore, a CAR term is modeled into the mean regression equation to account for spatial random effects. These types of models have been extensively used to analyze road crash data at different scales due to the simplicity of the model structure and easy of use in the context of Bayesian inference.

Aguero-Valverde and Jovanis (2006), for example, compared Full Bayes hierarchical models and compared them with traditional negative binomial models to estimate annual crash frequencies at the county level using a multi-year range dataset (1996-2000) in Pennsylvania, USA. The authors developed a conditional autoregressive model (CAR) to analyze spatial relationships, time trend and space-time interactions. They used a timecoefficient to show temporal impacts and display space-time interactions using CAR random impacts for every county times the time trend. Spatial correlation was found in the data at the county level using Full Bayes hierarchical 
models, implying that these spatial correlations are likely to be more pronounced at smaller scales, such as segment and intersection levels.

Song, Ghosh, Miaou, and Mallick (2006) studied a spatial approach and used several Bayesian multivariate models to estimate the crash rates from different types of crashes. Multivariate conditional autoregressive (CAR) models are considered to account for the spatial effect and provided several spatial priors for Bayesian multivariate hierarchical models and sufficient conditions to ensure posterior propriety under non informative prior for all the proposed models. Aguero-Valverde and Jovanis (2008) also used Full Bayes with the purpose of better understanding the effects of spatial correlation in relation to road safety analysis. They analyzed the effect of spatial correlation in models of road crash frequency at the segment level and highlighted the potential of spatial correlation to reduce bias associated with model misspecification. They used a diverse contingent of structures through the weights in the neighboring matrices of the CAR model and proposed using the reverse of the adjacency (as characterized by proximity) as weight in the CAR model. Their study showed that given a 'reasonable' spatial prior, a high extent of heterogeneity is explained by the spatial correlation term.

Aguero also analyzed the effect of direct spatial correlation structures on crash frequency models by developing Full Bayes Hierarchical models with direct spatial correlation and conditional autoregressive spatial effects. The author found that the direct spatial correlation model presented a better goodness-of-fit than the CAR model and that a similar proportion of variation in the data was explained by spatial correlation in both models.

Bayesian models are able to handle very complex models. They use simulation methods to generate drawings from the posterior distribution, and have been commonly implemented with the use of MCMC methods. These can be defined as a sampling-based approach to estimation methods. By randomly sampling values out of the distribution, MCMC methods allow to characterize a distribution without knowing all of the distribution's mathematical properties (Van Ravenzwaaij, Cassey, \& Brown, 2018). Because of the focus on posterior distributions, and because they can handle complex model forms, MCMC are well-suited for Bayesian models. However, they are not without any problems. Problems in terms of convergence or computational time are often cited in literature (Rue et al. 2009). The simulation time being dependent on the sample size and on the model complexity, these can still be a barrier to developing more complex model forms (Lord \& Mannering, 2010). These issues have led to the Integrated Nested Laplace Approximation (INLA) approach (Rue et al. 2009). Developed over the past decade, INLA has been increasingly used as an alternative to MCMC methods due to its improved computation capabilities. INLA was designed for a wide range of models, including spatial and spatio-temporal models and has allowed to overcome some of the challenges encountered with the MCMC methods 
notably in terms of computational time and when dealing with complex Bayesian models (Rue et al. 2009). This recent approach has been used in road crash analyses as they allow to specify more accurate prior distributions and to take into account the spatial and temporal structure of crash in the inferential process which is then used to derive posterior distributions (Blangiardo, Cameletti, Baio, \& Rue, 2013; Wang, Ivan, Ravishanker, \& Jackson, 2017).

$\mathrm{Hu}$, Ivan, Ravishanker, and Mooradian (2013) for example, considered dynamic time series modeling in a Bayesian framework to reveal temporal patterns in highway crashes. They demonstrated that these dynamic models fit the data better than the typical GLM framework while allowing the discovery of temporal patterns in the estimation of parameters. They also found that some computational challenges emerging from Markov Chain Monte Carlo (MCMC) procedures can be handled by the innovative Integrated Nested Laplace Approximations (INLA).

Serhiyenko, Ivan, Ravishanker, and Islam (2014) used INLA to investigate how the extents of various damage severity levels might change after some time in respect to each other, and to evaluate how pedestrian safety has changed over the observational period. They actualized the Integrated Nested Laplace Approximation (INLA) approach to deal with fast Bayesian posterior calculation. They compared two different approaches for estimating pedestrian crash counts by damage severity level, the Dynamic Setup and the Static Setup. Their findings showed that there was a perceptible shift in the extent of pedestrian crashes from severe to minor injury, while the increase of fatal was extremely small over time.

In another study Serhiyenko, Mamun, Ivan, and Ravishanker (2016) explored the multivariate Poisson Log normal (MPLN) model of counts for different types of crashes. The MPLN model is demonstrated using INLA, which gives a quick instrument to Bayesian inference in view of exact approximations to the posterior distributions of the parameters. The Bayesian MPLN model for crash counting demonstrates that the increase of the annual average daily traffic and segment length result in the increase of crash frequency for all three crash types. Statistical analysis showed that raised type of medians are related to a reduction in the same direction and single vehicle crashes, in any case, presence of Jersey type median increases the same direction crashes for six and eight path constrained access highways.

Wang et al. (2017) contemplated Multivariate Poisson Log Normal (MVPLN) model to evaluate crashes by both crash type and crash severity utilizing the Integrated Nested Laplace Approximation (INLA). The authors found that the correlation in MVPLN models of crash counts are significant by crash type and severity, which demonstrates that the MVPLN model can prompt more precise variance estimates by representing the possible correlations among crash type and severity counts. 
The literature shows that analyses of road traffic crashes have used CAR models as well as INLA models; but the combinations of INLA-CAR models are seldom used in literature. Bayesian models could greatly benefit from the power of INLA, which is an alternative approach to other software applications, such as OpenBUGS, used to undertake Bayesian analyses of complex statistical models with the MCMC method and presents the advantage of being much faster to run and a better fit to develop CAR models. In this paper, a Bayesian method is developed to analyze traffic crash on a highway section using the INLA approach.

\section{Methodology}

This section describes the general model specification used in the present research, as follows equations (Aguero-Valverde, 2011):

$$
Y_{\text {it }} \sim \text { Poisson }\left(\theta_{i t}\right)
$$

where:

$\mathrm{y}_{\mathrm{it}}$ are the observed number of crashes in segment $i$ at time $t$ (in years), $\theta_{\text {it }}$ are the expected Poisson rate (i.e., expected crash frequency) for segment $i$ at time $t$.

The Poisson rate is modeled as a function of the covariates following the log-normal distributionstated below:

$$
\log \left(\theta_{i t}\right)=\beta_{0}+\sum_{k} \beta_{k} x_{i t k}+\varepsilon_{i t}
$$

where:

$\beta_{0}$ is the intercept,

$\beta_{\mathrm{k}}$ is the coefficient for the $\mathrm{k}^{\text {th }}$ covariate,

$\mathrm{x}_{\mathrm{itk}}$ is the value for the $\mathrm{k}^{\text {th }}$ covariate (or any suitable transformation of the covariate), for segment $i$, at time $\mathrm{t}$ and $\varepsilon_{\mathrm{it}}$ is the error term for segment $i$ at time $t$.

A Poisson model with a Besag York Mollie (BYM) specification (spatial term) is assumed and applied in Bayesian framework using the INLA (Integrated Nested Laplace approximations) approach (more detail see (Besag, York, \& Mollié, 1991). This model is in fact, a union of the Besag model or Conditionally Autoregressive term $u$ and an independent identically distributed (iid) error term $v$. The benefit is that it allows getting the posterior marginal of the sum of the spatial and iid model:

$$
\varepsilon_{i t}=\left(\begin{array}{c}
v_{i t}+u_{i t} \\
u_{i t}
\end{array}\right)
$$

With the length of $\mathrm{x}$ being $2 \mathrm{n}$ if the lengths of $\mathrm{u}$ (and $\mathrm{v}$ ) is $\mathrm{n}$. Then $v$ is defined as:

$$
V_{i} \sim N\left(O, \tau_{v}\right)
$$

where: 
$\tau_{v}$ is the precision (inverse of the variance) and controls the Poisson extravariation due to heterogeneity.

The random effects are pooled over time to improve the model estimation. The assumption of constant random effects over time is not restrictive, provided that the covariates explain most of this variation over time.

The spatially correlated effect is modeled using a Gaussian Conditional Autoregressive (CAR)prior (Besag et al., 1991):

$$
\left.u_{i} \mid u_{-i} \sim N \frac{\sum_{j-i} W_{i j} U_{j}}{W_{i+}}, \frac{1}{W_{i+} \tau_{u}}\right)
$$

where: $\mathrm{u}_{-\mathrm{I}}$ refers to all the neighbors of $i, \tau_{u}$ controls the Poisson extravariation due to clustering orspatial correlation, denotes that segment $j$ is a neighbor of segment $i, \mathrm{w}_{\mathrm{ij}}$ is the weight of the $\mathrm{j}^{\text {th }}$ neighbor of the $\mathrm{i}^{\text {th }}$ segment, and $\mathrm{w}_{\mathrm{i}+}$ is the sum of the weights of the neighbors of segment $i$.

The hyperparameters are the precision $\tau_{v 1}$ of the iid model $(v)$ and the precision $\tau_{u}$ of the spatial model $(u)$. The precision parameters are represented as:

$$
\tau=\left(\theta_{v 1}, \theta_{u 1}\right)=\left(\log \tau_{v}, \log , \tau_{u}\right)
$$

And the priors are defined on $\tau$ such as $\tau_{v}, \tau_{u} \sim \operatorname{loggamma}\left(1,5 \times 10^{-4}\right)$.

This paper uses the recently proposed INLA approach (Rue et al., 2009) which gives an instrument to Bayesian derivation regarding the precise approximations to the posterior distributions of the parameters. Since INLA does not depend on Markov Chain Monte Carlo, the rough approach significantly diminishes the required amount of computational time. More details on the approach and also the R-INLA package are accessible on the website (htpp://www.r.- inla.org/) (Sauter and Held, 2015; Rue \& Martino, 2007).

\subsection{Goodness of fit measures}

Goodness-of-fit measures aim to compare and select models that provide the best fit to the data. As explained in Spiegelhalter, Best, Carlin, and Van Der Linde (2002), model comparison is done by defining a measure of fit to the data and a measure of complexity in the model, the latter represented by the number of parameters in the model. Increase in model complexity is associated with a better fit to the data, and model comparison is usually done by trading these two elements (Spiegelhalter et al., 2002; Pooley \& Marion, 2018).

The Deviance Information Criteria (DIC) developed by Spiegelhalter et al. (2002) is a commonly used goodness-of-fit measure to assess the performance of Bayesian models. It assumes the two measures of fit and complexity such as: 


$$
D I C=\bar{D}+p_{D}
$$

where $\bar{D}$ is the posterior deviance and measures the model fit and $p_{D}$ is the effective number of parameters and measures the model complexity.

The DIC measure can also be expressed as:

$$
D I C=D(\bar{\theta})+2 p_{D}
$$

where $D(\bar{\theta})$ is the deviance at the posterior mean $\theta$.

Other measures include the Bayesian Information Criterion (BIC), the Akaike Information Criterion (AIC), the Posterior Deviance mean, and the Watanabe-Akaike information criterion (WAIC). A large number of studies have been dedicated to comparing the results of these different goodnessof-fit measures (Gelman, Hwang, \& Vehtari, 2013; Pooley \& Marion, 2018). In traffic crashes modeling where Bayesian models are extensively applied, the DIC is a popular indicator used for model selection. Its simplicity to use, its application to a wide range of models and its integration in the BUGS software are some of the reasons contributing to explain its popular use (Spiegelhalter et al., 2002; Berg, Meyer, \& Yu, 2004; Geedipally, Lord, \& Dhavala, 2014).

However, some studies have highlighted a certain number of caveats with using the DIC as a model comparison criterion. For example, Plummer (2008) showed that DIC can lack consistency to identify the best model and tends to under-penalize complex models. Geedipally et al. (2014) found that in certain types of models such as Poisson Gamma and Negative Binomial, the output of the DIC is influenced by the model parametrization and the authors recommended to consider other model performance measure in addition to using the DIC. Pooley and Marion (2018) compared the performance of the DIC against another performance measure, model evidence, and highlighted a lack of consistency from the DIC in selecting the best model.

To assess the results of the DIC, the Watanabe-Akaike information criterion (WAIC) and the Logarithm of the pseudo marginal likelihood (LPML) are used in addition to the posterior deviance as two other goodness-of-fit measures to cross-validate the results of the DIC.

The Watanabe-Akaike information criterion is used to estimate the outof-sample expectation. It computes the log pointwise posterior predictive density and add a correction for effective number of parameters in order to adjust over fitting (Gelman et al., 2013). While the use of this criterion is also associated with certain limitations (Gelman et al., 2013), it presents the advantage to be invariant to reparameterization and can deal with mixture models (Spiegelhalter et al. 2014). WAIC is expressed as:

$$
W A I C=-2 *\left(L P P D-p_{D}\right)
$$


where $p_{D}$ is an estimate of the effective number of parameters in the model and LPPD is the log posterior predictive density estimated as:

$$
L P P D=\sum_{i=1}^{n} \log \int p\left(y_{i} \mid \theta\right) p_{\text {post }}(\theta) d \theta
$$

The Logarithm of the pseudo marginal likelihood can be expressed as:

$$
L P M L=\sum_{i=1}^{n} \log \left(C P O_{i}\right)(11)
$$

where $\mathrm{CPO}$ is the Conditional Predictive Ordinate defined as:

$$
C P O_{i}=f\left(y_{i} \mid \boldsymbol{y}_{-i}\right)
$$

where $\mathrm{y}_{i}$ is the $i$ th observation for all segments

\subsection{Elasticity}

Elasticities are calculated to assess the impacts of each variable. More precisely, they measure the magnitude of impact of individual variables on the outcome probabilities (Moore, Schneider, Savolainen, \& Farzaneh, 2011, Chen \& Chen, 2011). For discrete variables (i.e., for variables defined by 0 or 1 values), pseudo-elasticities are calculated. The former measures the effect that a $1 \%$ change in the value of a variable has on the outcome probability.

Pseudo elasticity can be computed as follow (Washington, Karlaftis, \& Mannering, 2003):

$$
E_{x_{i j}}^{\lambda_{i}}=\frac{\operatorname{EXP}\left(\beta_{j}\right)-1}{\operatorname{EXP}\left(\beta_{j}\right)} \times 100
$$

where $\left(\beta_{j}\right)$ estimated parameter for the Jth independent variable. With Eq. 13 , pseudo elasticity gives the percent change in then expected frequency of change orders $\lambda_{i}$, associated with a change in the value of the indicator variable from 0 to 1 .

\section{Study area and data}

The study area of this analysis is located in Indonesia's Aceh province in the northern end of Sumatra Island. The province's area is around $58.377 \mathrm{~km} 2$, covered with urban, suburban, hilly and mountainous areas. As of 2017, the Aceh recorded an estimated 5.19 million inhabitants. The studied road is a $225 \mathrm{~km}$ long road segment between Banda Aceh and Bireun and is part of the main road going from Banda Aceh to Medan. For the purpose of this analysis, the studied road is split into 190 segments and recording 457 crash records Figure 1 presents the location of the studied area. The road is a primary arterial road with two lanes, and accommodates traffic flow from the western part to the eastern part of the province. It 


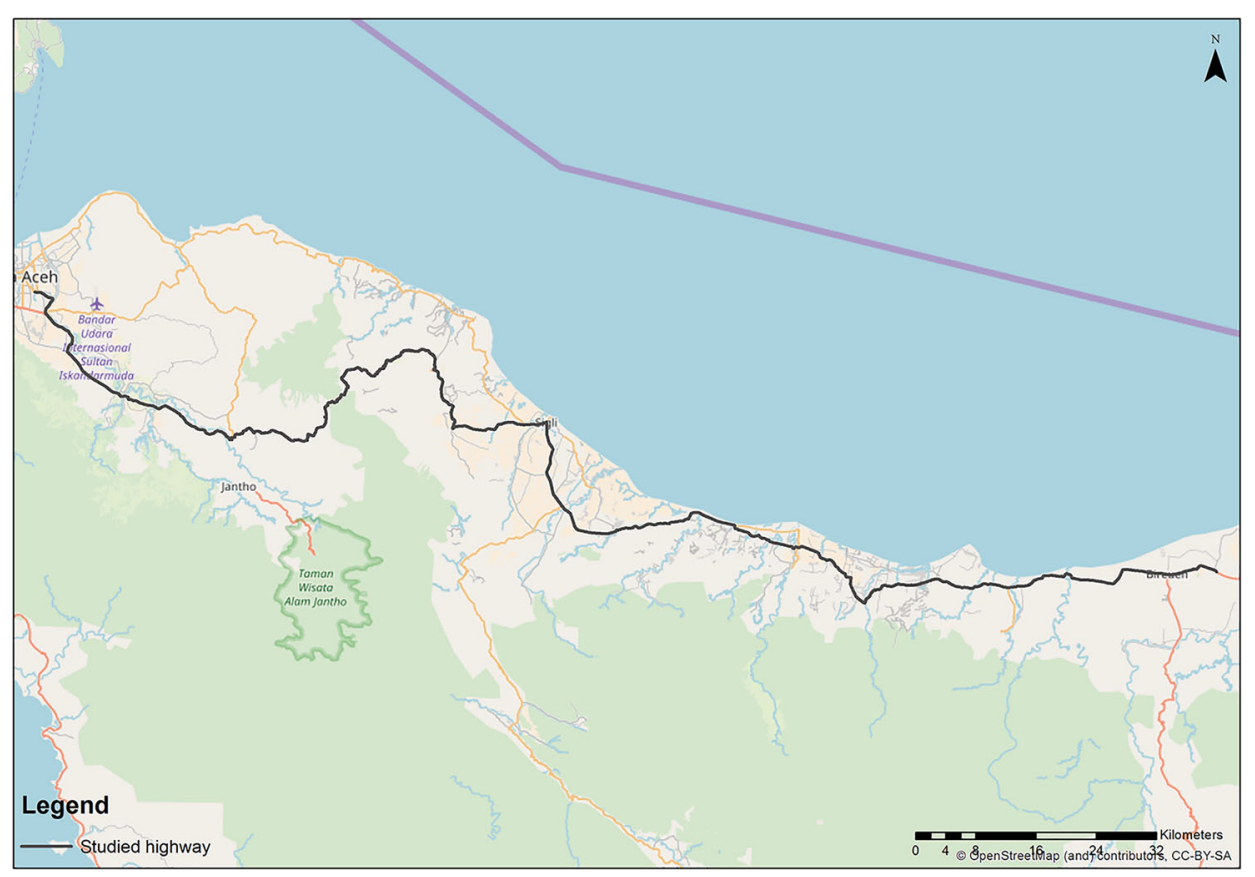

Figure 1. Localization of the studied area.

absorbs heavy traffic such as trucks, buses, and other types of fourwheeled vehicles.

Two different datasets were used in this study, the first one (crash data) was provided by The Traffic police department of the Province of Aceh and the second one (road inventory) by the Department of Public Work also from the Province of Aceh province in Indonesia.

\subsection{Crash data}

The road crash dataset provides information on 457 road crashes that have been recorded on this road segment between 2012 and 2015. A crash record (also referred to as road crash record) is defined as a crash in which either a personal injury has occurred or in which a vehicle has been towed away from the crash location. Information collected includes localization of the crashes (reported as longitude and latitude), as well as a series of attribute information such as severity of the crash, profile of the person injured, name of the road or type of crash. Table 1 provides a summary description of the different variables characterizing the crash.

The number of road crashes and the level of crash severity have been extensively applied as indicator for measuring the efficiency of service provision in road network systems in each country. In addition, the implication of crash level can help policy makers to develop appropriate policies 
Table 1. Description of crash record variables in this study.

\begin{tabular}{|c|c|c|}
\hline Variable & Description & Accepted values \\
\hline Weather condition & Weather condition when crash occurred & $\begin{array}{l}1 \text { (bright), } 2 \text { (foggy), } 2 \text { (cloudy), } 4 \\
\text { (rain), } 5 \text { (windy) }\end{array}$ \\
\hline Light condition & Lighting condition when crash occurred & 1 (bright), 2 (dim), 3 (dark) \\
\hline Crash Location(decimal degree) & $\begin{array}{l}\text { Location where the crash occurred } \\
\text { defined its latitude and longitude }\end{array}$ & $\begin{array}{l}\text { Latitude and longitude in decimal } \\
\text { degree of the emplacement } \\
\text { where the crash occurred }\end{array}$ \\
\hline $\begin{array}{l}\text { Fatality } \\
\text { (number of victims) }\end{array}$ & Occurrence of death by crash & $\begin{array}{l}\text { Value ranging from } 0 \text { to } 7 \\
\text { persons who died in a single } \\
\text { road crashes }\end{array}$ \\
\hline $\begin{array}{l}\text { Serious injury } \\
\text { Number of victims) }\end{array}$ & Occurrence of serious injury by crash & $\begin{array}{l}\text { Value ranges from } 0 \text { to } 20 \\
\text { persons who died in a single } \\
\text { road crashes }\end{array}$ \\
\hline $\begin{array}{l}\text { Minor injury (Number } \\
\text { of victims) }\end{array}$ & Occurrence of minor injury by crash & $\begin{array}{l}\text { Value ranges from } 0 \text { to } 12 \\
\text { persons who died }\end{array}$ \\
\hline Speed limit $(\mathrm{km} / \mathrm{h})$ & $\begin{array}{l}\text { Speed limit on the roadway where the } \\
\text { crash occurred }\end{array}$ & \\
\hline District & $\begin{array}{l}\text { District name in which the } \\
\text { crash occurred }\end{array}$ & $\begin{array}{l}\text { Accepted values: } \\
\text { 'Aceh Besar' } \\
\text { 'Band Aceh' } \\
\text { 'Bireun' } \\
\text { 'Pidie' }\end{array}$ \\
\hline Land use & Land use type covering the area & Rural, Rural-Urban, Urban \\
\hline Alignment vertical & A series of vertical alignment of the road & 1 (flat), 4 (rolling) \\
\hline Alignment horizontal & $\begin{array}{l}\text { A series of horizontal alignment of } \\
\text { the road }\end{array}$ & $\begin{array}{l}2 \text { (straight), } 3 \text { (meandering), } \\
5 \text { (windy) }\end{array}$ \\
\hline $\begin{array}{l}\text { Annual average daily traffic } \\
\text { (AADT) (Number of vehicles) }\end{array}$ & $\begin{array}{l}\text { The total volume of vehicle traffic of } \\
\text { the road }\end{array}$ & $\begin{array}{l}\text { Varying values across the } \\
\text { different segments }\end{array}$ \\
\hline Width of ditch (meter) & Width of ditch & 1 \\
\hline Width of shoulder (meter) & Width of shoulder & 1 \\
\hline Width of surface (meter) & A measurement of width of surface & 7 \\
\hline Median (meter) & Median of the road & 0 \\
\hline Density access (\# access/km) & $\begin{array}{l}\text { Density of access in each segment } \\
\text { calculated by the total number of } \\
\text { access in the segment dividing by the } \\
\text { total length in } \mathrm{km} \text { of the segment }\end{array}$ & $\begin{array}{l}\text { Varying values across the } \\
\text { different segments }\end{array}$ \\
\hline Length (km) & Varying values across the segments & meter \\
\hline
\end{tabular}

in order to reduce the number of crashes on roads. Furthermore, it will be a good contribution for governments all over the world to analyze black spots and hot zones based on severity level.

\subsection{Road inventory}

Information about the road segment dataset was obtained from the Department of Public Work of Banda Aceh Road Management System and includes information on the different districts, the number of segments, the length, the average annual daily traffic (AADT), the width of ditch, surface and shoulder, the type of geometry and the type of land use.

Two spatial databases were created from the traffic crashes records and road section attributes collected.

The first database compiled attributes information of traffic crash that occurred on the section highway between Banda Aceh and Bireun between 
Table 2. Summary statistics of the data.

\begin{tabular}{|c|c|c|c|c|}
\hline Variable & Mean & Std. Dev & Min & Max \\
\hline Crashes & 5.2 & 10.4 & 0 & 86 \\
\hline Fatal Crashes & 1 & 1.9 & 0 & 17 \\
\hline Major crashes & 1.4 & 3.1 & 0 & 32 \\
\hline Minor crashes & 2.7 & 6.2 & 0 & 47 \\
\hline PDO & 4.5 & 9.1 & 0 & 79 \\
\hline AADT & 14598.6 & 112079.6 & 4878 & 41706 \\
\hline Length & 1.2 & 0.9 & 0 & 7 \\
\hline Speed limit & 75.5 & 17.8 & 60 & 100 \\
\hline Variable & Number segments & $\begin{array}{l}\text { Total length } \\
(\mathbf{k m})\end{array}$ & $\begin{array}{l}\text { Proportion } \\
\quad \text { segments (\%) }\end{array}$ & $\begin{array}{l}\text { Proportion } \\
\quad \text { length (\%) }\end{array}$ \\
\hline Land use urban & 99 & 117.9 & 53.2 & 53.8 \\
\hline Land use urban-rural & 30 & 28.7 & 16.1 & 13.1 \\
\hline Land use rural & 57 & 72.4 & 30.6 & 33.1 \\
\hline Horizontal alignment straight & 53 & 69.2 & 28.5 & 31.6 \\
\hline Horizontal alignment meandering & 124 & 139.8 & 66.6 & 63.8 \\
\hline Horizontal alignment windy & 9 & 9.9 & 4.8 & 4.5 \\
\hline
\end{tabular}

2012 and 2015. In total, 457 crash records were integrated in the database and georeferenced through their GPS coordinates. Traffic crash for which no coordinates were provided were excluded from the analysis. Attribute information of each record was then quality checked and standardized to the database schema

The second database compiled information about the $225 \mathrm{~km}$ long road section analyzed in this study. The polyline characterizing the road was quality checked to ensure its continuity across the section. Attribute information was also quality checked and added into the database schema. Summary statistics of the data are shown in the Table 2. They include the mean, the standard deviation (Std. Dev) as well as the minimum (Min) and maximum (Max) values of the road section analyzed and of the crash variables.

\section{Results and discussion}

In total, ten models were developed and run: the spatial and non-spatial models were applied on five different levels of crash severity: total, fatal, major injury, minor injury and property damage only (PDO) (see Table 1 for variable description). Annual average daily traffic (AADT) was included in the models as a key parameter contributing to explain road traffic crashes. The variables land use 'urban' and alignment flat were selected as base case. The segment length was incorporated as an offset in the models (i.e., the natural logarithm, of the segment length has a fixed coefficient equal to 1). To select the final spatial and non-spatial models, a generalized linear model was developed and the variables with the lower AIC were included in the final spatial and non-spatial models used below. Vertical alignment and density access were not significant and were therefore removed from the final models. Speed limit and land use were perfectly 
Table 3. Comparative results of three goodness-of-fit measures for the spatial and non-spatial models of the different crash scenarios.

\begin{tabular}{lccccccccc}
\hline & $\begin{array}{c}\text { DIC } \\
\text { (Spatial } \\
\text { model) }\end{array}$ & $\begin{array}{c}\text { DIC } \\
\text { mon-spatial } \\
\text { model) }\end{array}$ & $\begin{array}{c}\text { Difference } \\
\text { of DIC }\end{array}$ & $\begin{array}{c}\text { Deviance } \\
\text { (Spatial } \\
\text { model) }\end{array}$ & $\begin{array}{c}\text { Deviance } \\
\text { (Non-spatial } \\
\text { model) }\end{array}$ & $\begin{array}{c}\text { WAIC } \\
\text { (Spatial } \\
\text { model) }\end{array}$ & $\begin{array}{c}\text { WolC } \\
\text { (Non-spatial } \\
\text { model) }\end{array}$ & $\begin{array}{c}\text { LPML } \\
\text { (Spatial } \\
\text { model) }\end{array}$ & $\begin{array}{c}\text { LPML } \\
\text { (Non-spatial } \\
\text { model) }\end{array}$ \\
\hline Total crashes & 663.72 & 723.60 & 59.88 & 258.86 & 315.19 & 646.06 & 727.46 & -1176.31 & -1445.32 \\
$\begin{array}{l}\text { Fatal crashes } \\
359.34\end{array}$ & 397.82 & 38.48 & 177.78 & 214.44 & 350.06 & 386.23 & -793.89 & -1446.20 \\
$\begin{array}{c}\text { Major injury } \\
\text { crashes }\end{array}$ & 403.13 & 450.73 & 47.60 & 189.40 & 237.64 & 390.63 & 438.24 & -796.25 & -1375.52 \\
$\begin{array}{c}\text { Minor injury } \\
\text { crashes }\end{array}$ & 440.83 & 512.03 & 71.20 & 188.82 & 258.40 & 424.85 & 503.20 & -1000.63 & -1508.10 \\
PDO crashes & 565.67 & 630.70 & 65.03 & 233.16 & 295.53 & 547.07 & 620.78 & -1085.92 & -1409.54 \\
\hline
\end{tabular}

collinear, therefore only one of these variables (in this case, land use) was included in the final models. The important collinearity between the two variables means that it would have been difficult to accurately assess the contribution of predictors to the models. Land use was selected in the model over speed limit because it returns a lower DIC value indicating a better fit to the model

Generally, it can be seen that the spatial model performed better than the non-spatial model for all severities, as indicated by lower values of the DIC, Deviance, WAIC, and higher LPML values for the spatial models compared with the non-spatial model (Table 3). Across all severities, the difference in DIC between the spatial model and the non-spatial model is higher than 38 points. When considering total crashes, the spatial model predicted crashes better, with DIC values lower by more than 59 points compared to the DIC value of the non-spatial model. Similarly, the Deviance and WAIC values are also lower in the spatial model (258.86 and 646.06 respectively) than those of the non-spatial (315.19 and 727.46 respectively). The higher LPML value for the spatial model (-1176.31) compared to the LPML value of the non-spatial model (-1445.32) also indicates that the spatial model performs better than the non-spatial one.

In the fatal crashes scenario, the difference in DIC between the spatial model and the non-spatial model is of approximately 38 points. These results are consistent with previous works that have found significant improvements in goodness-of-fit measures for spatial models at the segment level (Aguero-Valverde \& Jovanis, 2008; El-Basyouny \& Sayed, 2009; Huang \& Abdel-Aty, 2010; Guo, Xu, Pei, Wong, \& Yao, 2017; Huang, Zhou, Wang, Chang, \& Ma, 2017).

Table 4 presents the estimates of the spatial and non-spatial models for the total number of crashes. The variables land use 'urban' and horizontal alignment 'flat' were used as the base case in all the models. In addition, the length of the segment (in $\mathrm{km}^{2}$ ) was used as an offset for the models. The coefficient for AADT is 1.058 and the mean values of the land use variables were -0.496 (urban and rural) and -0.350 (rural). The estimates of the non-spatial model 
Table 4. Models of total crash frequency.

\begin{tabular}{|c|c|c|c|c|c|c|c|c|c|c|}
\hline \multirow[b]{3}{*}{ Variable } & \multicolumn{5}{|c|}{ Spatial Model } & \multicolumn{5}{|c|}{ Non-Spatial model } \\
\hline & \multirow[b]{2}{*}{ Mean } & \multirow[b]{2}{*}{ SD } & \multicolumn{3}{|c|}{ Quantile } & \multirow[b]{2}{*}{ Mean } & \multirow[b]{2}{*}{ SD } & \multicolumn{3}{|c|}{ Quantile } \\
\hline & & & 0.025 & 0.5 & 0.975 & & & 0.025 & 0.5 & 0.975 \\
\hline (Intercept) & -10.867 & 3.207 & -17.377 & -10.800 & -4.731 & -15.457 & 2.972 & -21.572 & -15.358 & -9.901 \\
\hline $\log (A A D T)$ & 1.058 & 0.336 & 0.413 & 1.053 & 1.736 & 1.596 & 0.304 & 1.025 & 1.587 & 2.222 \\
\hline $\begin{array}{l}\text { Horizontal alignment } \\
\text { (Meandering) }\end{array}$ & -0.496 & 0.403 & -1.304 & -0.491 & 0.282 & -1.391 & 0.610 & -2.627 & -1.378 & -0.225 \\
\hline alignment hor (Windy) & -0.350 & 0.313 & -0.973 & -0.348 & 0.261 & -0.463 & 0.468 & -1.391 & -0.461 & 0.451 \\
\hline $\begin{array}{l}\text { land use (Urban } \\
\text { and rural) }\end{array}$ & -0.189 & 0.309 & -0.797 & -0.189 & 0.418 & -0.489 & 0.438 & -1.353 & -0.488 & 0.371 \\
\hline land use (Rural) & 0.742 & 0.723 & -0.678 & 0.741 & 2.168 & 0.843 & 0.988 & -1.102 & 0.843 & 2.786 \\
\hline$\tau_{v}$ & 0.763 & & & & & & & & & \\
\hline$\tau_{u}$ & 6.569 & & & & & & & & & \\
\hline $\begin{array}{l}\text { Expected number of } \\
\text { effect parameters }\end{array}$ & 109.94 & & & & & 142.18 & & & & \\
\hline DIC & 663.72 & & & & & 723.60 & & & & \\
\hline Segments (number) & 190 & & & & & & & & & \\
\hline Crash records & 457 & & & & & & & & & \\
\hline
\end{tabular}

return a mean of log AADT of 1.596 , and a mean of -0.489 for the horizontal alignment variable meandering and of 0.843 for the horizontal alignment variable windy. The mean values of the land use variables were -1.391 for urban and rural and -0.463 for rural. The expected values of the coefficient estimates between the spatial and non-spatial models for the severity type total number of crashes shows significant differences. The coefficient for AADT in the spatial model is approximately $50 \%$ lower than in the non-spatial model. These findings are consistent with results found in other studies showing that the bias associated with model misspecification can be reduced by including spatial correlation as illustrated by the reduction of the AADT coefficient ((Vogt \& Bared, 1998; Qin, Ivan, \& Ravishanker, 2004; Aguero-Valverde \& Jovanis, 2008; Aguero-Valverde, Wu, \& Donnell, 2016).

The spatial model also significantly improves the coefficient estimates of the land use variables: the mean value the land use variable rural being -0.350 in the spatial model and -0.453 in the non-spatial model. These results indicate that the expected number of total crashes in rural areas is lower than in urban areas (base case). These results are consistent with findings in the existing literature (Ivan, Wang, \& Bernardo, 2000; Pulugurtha, Duddu, \& Kotagiri, 2013; Osama \& Sayed, 2017).

With regards to horizontal alignment, the spatial model returns a less significant estimate for the horizontal alignment variable windy (0.742) than it does in the non-spatial model (0.843). These findings are not consistent with other studies on the relations between horizontal alignment and crashes (Montella, Colantuoni, \& Lamberti, 2008; Karlaftis \& Golias, 2002; Ma, Kockelman, \& Damien, 2008).

Table 5 presents the estimates of the severity type fatal crashes. The table shows that the AADT coefficients of both models are significant and have 
Table 5. Models of fatal crash frequency.

\begin{tabular}{|c|c|c|c|c|c|c|c|c|c|c|}
\hline \multirow[b]{3}{*}{ Variable } & \multicolumn{5}{|c|}{ Spatial Model } & \multicolumn{5}{|c|}{ Non-Spatial model } \\
\hline & & & \multicolumn{5}{|c|}{ Quantile } & \multicolumn{3}{|c|}{ Quantile } \\
\hline & Mean & SD & 0.025 & 0.5 & 0.975 & Mean & SD & 0.025 & 0.5 & 0.975 \\
\hline (Intercept) & -7.451 & 2.598 & -12.705 & -7.403 & -2.468 & -7.686 & 2.210 & -12.216 & -7.620 & -3.528 \\
\hline $\log (A A D T)$ & 0.523 & 0.270 & 0.002 & 0.520 & 1.063 & 0.616 & 0.225 & 0.191 & 0.610 & 1.076 \\
\hline $\begin{array}{l}\text { alignment hor } \\
\text { (Meandering) }\end{array}$ & -0.412 & 0.477 & -1.387 & -0.398 & 0.487 & -1.072 & 0.516 & -2.140 & -1.054 & -0.111 \\
\hline $\begin{array}{l}\text { alignment } \\
\text { hor (Windy) }\end{array}$ & -0.524 & 0.355 & -1.237 & -0.519 & 0.158 & -0.921 & 0.390 & -1.710 & -0.913 & -0.176 \\
\hline $\begin{array}{l}\text { land use (Urban } \\
\text { and rural) }\end{array}$ & 0.020 & 0.315 & -0.597 & 0.019 & 0.642 & -0.231 & 0.336 & -0.896 & -0.230 & 0.428 \\
\hline land use (Rural) & 1.060 & 0.782 & -0.484 & 1.061 & 2.596 & 0.566 & 0.815 & -1.080 & 0.580 & 2.130 \\
\hline$\tau_{v}$ & 1.11 & & & & & & & & & \\
\hline$\tau_{u}$ & 28.31 & & & & & & & & & \\
\hline $\begin{array}{l}\text { Expected number of } \\
\text { effect parameters }\end{array}$ & 62.89 & & & & & 85.71 & & & & \\
\hline DIC & 359.34 & & & & & 397.82 & & & & \\
\hline Segments (number) & 190 & & & & & & & & & \\
\hline Crash records & 457 & & & & & & & & & \\
\hline
\end{tabular}

positive values but that the estimate of the spatial model $(0.523)$ is lower than the estimate of the non-spatial (0.616). This pattern is repeated for all scenarios, regardless of the severity type, where the coefficient estimate for AADT is consistently lower in the spatial model. The two land use variables land use are negatively correlated with fatal crash in both models. The horizontal alignment variable windy is positively correlated with fatal crash in both the spatial and non-spatial models. The horizontal alignment variable meandering is positively correlated with fatal crash in the spatial but is negatively correlated in the non-spatial model.

Table 6 presents the results of the spatial and non-spatial models for major injury crashes. It is shown that the AADT coefficient values are positive and significant in both models. The two land use variables land use are negatively correlated with major injury crashes in both models. The horizontal alignment meandering is also negatively correlated with major injury crashes in both models, however the horizontal alignment windy is positively correlated with major injury crashes in both the spatial and non-spatial models.

Table 7 shows the results of the spatial and non-spatial models for the severity type minor injury crashes. The variables AADT and horizontal alignment windy are significant and positively correlated with minor injury crashes in both the spatial and non-spatial models. Conversely, the land use variables and horizontal alignment meandering are negatively correlated with minor injury crashes in both models.

Finally, Table 8 presents the results of the spatial and non-spatial models for the last severity type: PDO crashes. Similar to the scenario minor injury crashes, the variables AADT and horizontal alignment windy are significant 
Table 6. Models of major injury crashes.

\begin{tabular}{|c|c|c|c|c|c|c|c|c|c|c|}
\hline \multirow[b]{3}{*}{ Variable } & \multicolumn{5}{|c|}{ Spatial Model } & \multicolumn{5}{|c|}{ Non-Spatial model } \\
\hline & \multirow[b]{2}{*}{ Mean } & \multicolumn{3}{|c|}{ Quantile } & \multirow[b]{2}{*}{0.975} & \multirow[b]{2}{*}{ Mean } & \multirow[b]{2}{*}{ SD } & \multicolumn{2}{|c|}{ Quantile } & \multirow[b]{2}{*}{0.975} \\
\hline & & SD & 0.025 & 0.5 & & & & 0.025 & 0.5 & \\
\hline (Intercept) & -8.163 & 2.927 & -14.079 & -8.115 & -2.513 & -8.473 & 2.113 & -12.826 & -8.401 & -4.527 \\
\hline $\log (A A D T)$ & 0.646 & 0.304 & 0.052 & 0.643 & 1.254 & 0.738 & 0.215 & 0.335 & 0.732 & 1.179 \\
\hline $\begin{array}{l}\text { alignment hor } \\
\text { (Meandering) }\end{array}$ & -0.451 & 0.445 & -1.359 & -0.439 & 0.391 & -0.944 & 0.489 & -1.951 & -0.928 & -0.029 \\
\hline $\begin{array}{l}\text { alignment hor } \\
\text { (Windy) }\end{array}$ & -0.336 & 0.321 & $-0.972-$ & -0.335 & 0.292 & -0.281 & 0.342 & -0.956 & -0.281 & 0.389 \\
\hline $\begin{array}{l}\text { land use (Urban } \\
\text { and rural) }\end{array}$ & -0.493 & 0.301 & $-1.086-$ & -0.493 & 0.098 & -0.593 & 0.312 & -1.212 & -0.591 & 0.018 \\
\hline land use (Rural) & 0.765 & 0.683 & -0.584 & 0.767 & 2.105 & 0.686 & 0.681 & -0.667 & 0.690 & 2.015 \\
\hline$\tau_{v}$ & 1.18 & & & & & & & & & \\
\hline$\tau_{u}$ & 14.25 & & & & & & & & & \\
\hline $\begin{array}{l}\text { Expected number } \\
\text { of effect parameters }\end{array}$ & 70.91 & & & & & 92.93 & & & & \\
\hline DIC & 403.13 & & & & & 450.73 & & & & \\
\hline Segments (number) & 190 & & & & & & & & & \\
\hline Crash records & 457 & & & & & & & & & \\
\hline
\end{tabular}

Table 7. Models of minor injury crashes.

\begin{tabular}{|c|c|c|c|c|c|c|c|c|c|c|}
\hline \multirow[b]{3}{*}{ Variable } & \multicolumn{5}{|c|}{ Spatial Model } & \multicolumn{5}{|c|}{ Non-Spatial model } \\
\hline & \multirow[b]{2}{*}{ Mean } & \multirow[b]{2}{*}{ SD } & \multicolumn{3}{|c|}{ Quantile } & \multirow[b]{2}{*}{ Mean } & \multirow[b]{2}{*}{ SD } & \multicolumn{3}{|c|}{ Quantile } \\
\hline & & & 0.025 & 0.5 & 0.975 & & & 0.025 & 0.5 & 0.975 \\
\hline (Intercept) & -7.748 & 3.605 & -15.091 & -7.665 & -0.874 & -11.342 & 2.722 & -16.964 & -11.244 & -5.898 \\
\hline $\log (A A D T)$ & 0.552 & 0.375 & -0.169 & 0.546 & 1.309 & 1.049 & 0.277 & 0.529 & 1.039 & 1.654 \\
\hline $\begin{array}{l}\text { alignment } \\
\text { hor (Meandering) }\end{array}$ & -0.189 & 0.459 & -1.113 & -0.181 & 0.692 & -1.079 & 0.592 & -2.291 & -1.062 & 1.386 \\
\hline $\begin{array}{l}\text { alignment } \\
\text { hor (Windy) }\end{array}$ & -0.123 & 0.329 & -0.770 & -0.123 & 0.523 & -0.187 & 0.431 & -1.034 & -0.187 & -0.008 \\
\hline $\begin{array}{l}\text { land use (Urban } \\
\text { and rural) }\end{array}$ & -0.214 & 0.331 & -0.867 & -0.213 & 0.434 & -0.660 & 0.402 & -1.459 & -0.658 & 0.101 \\
\hline land use (Rural) & 0.730 & 0.837 & -0.903 & 0.726 & 2.388 & 0.160 & 0.915 & -1.667 & 0.169 & 1.991 \\
\hline$\tau_{v}$ & 1.08 & & & & & & & & & \\
\hline$\tau_{u}$ & 4.97 & & & & & & & & & \\
\hline $\begin{array}{r}\text { Expected number of } \\
\text { effect parameters }\end{array}$ & 78.81 & & & & & 116.26 & & & & \\
\hline DIC & 440.83 & & & & & 512.03 & & & & \\
\hline Segments (number) & 190 & & & & & & & & & \\
\hline Crash records & 457 & & & & & & & & & \\
\hline
\end{tabular}

and positively correlated with PDO crashes in both the spatial and nonspatial models. The land use variables and horizontal alignment meandering are however negatively correlated with PDO crashes in both models.

Based on the above results, some countermeasures can be suggested to start addressing some of the factors identified as contributing to road crashes. AADT and land use, for example, were identified as being significant parameters across all scenarios. In areas with high volume of traffic, centerline rumble strips could be installed to prevent crashes occurring in undivided parts of the highways. It is also recommended to add road traffic signs to inform about traffic density on secondary roads, in order to encourage drivers to use secondary roads on some sections of the travel, 
Table 8. Models of property damage only.

\begin{tabular}{|c|c|c|c|c|c|c|c|c|c|c|}
\hline \multirow[b]{3}{*}{ Variable } & \multicolumn{5}{|c|}{ Spatial Model } & \multicolumn{5}{|c|}{ Non-Spatial model } \\
\hline & \multicolumn{5}{|c|}{ Quantile } & \multicolumn{5}{|c|}{ Quantile } \\
\hline & Mean & SD & 0.025 & 0.5 & 0.975 & Mean & SD & 0.025 & 0.5 & 0.975 \\
\hline (Intercept) & -9.151 & 3.024 & -15.282 & -9.091 & -1.132 & -12.103 & 2.560 & -17.357 & -12.023 & -7.303 \\
\hline $\log (A A D T)$ & 0.815 & 0.316 & 0.207 & 0.810 & 1.451 & 1.194 & 0.262 & 0.702 & 1.187 & 1.731 \\
\hline $\begin{array}{l}\text { alignment } \\
\text { hor (Meandering) }\end{array}$ & -0.263 & 0.409 & -1.083 & -0.257 & 0.525 & -1.035 & 0.537 & -2.121 & -1.024 & -0.009 \\
\hline $\begin{array}{l}\text { alignment } \\
\text { hor (Windy) }\end{array}$ & -0.202 & 0.314 & -0.824 & -0.200 & 0.411 & -0.308 & 0.408 & -1.116 & -0.306 & 0.490 \\
\hline $\begin{array}{l}\text { land use (Urban } \\
\text { and rural) }\end{array}$ & -0.271 & 0.305 & -0.871 & -0.271 & 0.331 & -0.506 & 0.380 & -1.256 & -0.505 & 0.241 \\
\hline land use (Rural) & 0.475 & 0.713 & -0.928 & 0.475 & 1.877 & 0.477 & 0.862 & -1.225 & 0.479 & 2.169 \\
\hline$\tau_{v}$ & 0.825 & & & & & & & & & \\
\hline$\tau_{u}$ & 9.133 & & & & & & & & & \\
\hline $\begin{array}{l}\text { Expected number of } \\
\text { effect parameters }\end{array}$ & 98.67 & & & & & 131.52 & & & & \\
\hline DIC & 565.67 & & & & & 630.70 & & & & \\
\hline Segments (number) & 190 & & & & & & & & & \\
\hline Crash records & 457 & & & & & & & & & \\
\hline
\end{tabular}

which may be less busy. In terms of land use, it is suggested to improve warning ahead of entering rural-urban and urban areas by adding more road signs. It is also suggested to decrease speed limit and improve monitoring in these areas by adding more fixed and mobile speed cameras; and to strengthen law enforcement by ensuring speed-related fines are paid.

In order to cross-check the results of the DIC, the Deviance, WAIC and LPML were also calculated and analyzed. As presented earlier, Table 3 presents a summary of the results of the three goodness-of-fit criteria of the spatial and non-spatial models for all crash severity types. Smaller values of DIC and WAIC, and higher values of LPML indicate better fit to the model.

As it can be seen, the four criterions indicate that the spatial model is significantly better than the non-spatial model.

As the results do not directly provide the magnitude of the effects of variables on the count component across different severity levels, elasticities are calculated. Table 9 presents a summary of the elasticity (or pseudo-elasticity) values calculated on the main variables shown to be significant in the models. As shown in the table, a $1 \%$ increase in AADT will result in an increase of crashes in all scenarios. For example, a $1 \%$ increase in AADT will result in a $40 \%$ increase in fatal crash as predicted by the non-spatial model. The nonspatial model predicts higher percentage probabilities than the spatial model for all scenarios. Land use rural is another variable that is predicted to increase the percentage of crash in all scenarios in both the spatial and nonspatial models. For example, the probability for fatal crashes in rural environments increases $65 \%$ in the spatial model and over $40 \%$ in the non-spatial model. Changes in the three other variables horizontal alignment meandering, windy and land use urban rural will result in a decrease of crashes in all scenarios in the non-spatial model, and in almost all scenarios in the spatial 
Table 9. Elasticity results of the spatial and non-spatial models.

\begin{tabular}{lcc}
\hline & Spatial Model & Non-spatial model \\
Variable & Elasticity & Elasticity \\
\hline Total crashes & & 79.73 \\
log(AADT) & 65.29 & -301.9 \\
Horizontal alignment (Meandering) & -64.21 & -58.88 \\
Horizontal alignment (Windy) & -41.91 & -63.07 \\
land use (Urban and rural) & -20.8 & 56.96 \\
land use (Rural) & 52.38 & 45.99 \\
Fatalities & & -192.1 \\
log(AADT) & 40.73 & -151.2 \\
Horizontal alignment (Meandering) & -50.98 & -25.99 \\
Horizontal alignment (Windy) & -68.88 & 43.22 \\
land use (Urban and rural) & 1.98 & 52.19 \\
land use (Rural) & 65.35 & -157 \\
Major injury & & -32.45 \\
log(AADT) & 47.59 & -24.72 \\
Horizontal alignment (Meandering) & -56.99 & 49.64 \\
Horizontal alignment (Windy) & -39.93 & \\
land use (Urban and rural) & -63.72 & 64.97 \\
land use (Rural) & 53.47 & -194.2 \\
Minor Injury & & -36.07 \\
log(AADT) & 42.42 & -65.86 \\
Horizontal alignment (Meandering) & -20.8 & 37.94 \\
Horizontal alignment (Windy) & -13.09 & -93.48 \\
land use (Urban and rural) & -23.86 & 14.79 \\
land use (Rural) & 1.81 & 69.7 \\
PDO & & -51.5 \\
log(AADT) & 55.74 & -30.08 \\
Horizontal alignment (Meandering) & 22.38 & 31.13 \\
Horizontal alignment (Windy) & 37.81 & \\
land use (Urban and rural) & & \\
land use (Rural) & & \\
\hline
\end{tabular}

models. The non-spatial model predicts a significantly more important decrease in fatal, major, minor, and PDO crashes on meandering roads than the spatial model. For example, the number of crashes in the major injury scenarios is expected to decrease by $56 \%$ in the spatial model and $157 \%$ in the non-spatial model. The number of crashes in windy conditions is also expected to decrease in both the spatial and non-spatial models in all scenarios, except in the PDO crash scenario where the spatial model estimates an increase of PDO crash on windy roads of about $22 \%$. In urban-rural environments, the non-spatial model predicts a decrease in crashes across all scenarios whereas the spatial model estimates a small increase of fatal crashes $(1.98 \%)$ and an increase of $31 \%$ PDO crashes in these environments.

\section{Conclusions}

The examination of crash, traffic, and road inventory data in Indonesia's Aceh province using INLA-CAR models showed the importance of incorporating and analyzing the spatial relationships in road crash models. The spatial models are consistently better in terms of the goodness-of-fit measure and precision estimates than the non-spatial models. 
The results of the spatial and non-spatial models showed that the AADT coefficient is the most influential parameter for crash when it is included in the model. In both the spatial and non-spatial models, the AADT coefficient returned positively correlated values in the total crashes, fatal crashes, major injury crashes, and minor injury crashes and PDO crashes scenarios. The AADT coefficient is consistently lower for spatial models, which shows that by including spatial error term, the bias associated with model missspecification can be reduced, The coefficients for land use and horizontal variables are negative in the total crashes scenarios but are positives in the fatal crashes scenarios. This means that the total crashes rate decreases in windy and meandering rural and urban rural environment whereas in the fatal scenarios the crashes rate increases in the same environment.

The three goodness-of-fit measures used to compare the results of the DIC provided consistent results with those of the DIC. All four criterions (DIC, posterior deviance, WAIC and LPML) indicated that the spatial model performed better than the non-spatial model. Despite some drawbacks associated with the DIC as published in the literature, the comparison of the latter with three other measures in this study found concordant results.

In Indonesia, few studies have analyzed traffic crashes and identified contributing factors. The results of the study can provide a theoretical support for decision-makers to analyze, more comprehensively, the key contributing factors leading to road crashes and establish basis to improve the safety performance of these roads. It is hoped that this study will generate further work to provide transportation agencies in Indonesia, and more particularly in the Aceh region with the necessary information to make informed decision to improve safety on its roads. This could include for example doing a comprehensive review of the most adequate measures to put in place under the local context.

Further work is needed to expand this analysis on all highways of the country, where crashes have been increasing rapidly so as to develop and implement appropriate and effective countermeasures.

Future work could look at developing a methodology to compare in a single approach if multivariate models are more critical than spatial correlation.

\section{Disclosure statement}

No potential conflict of interest was reported by the author(s).

\section{ORCID}

Jonathan Aguero-Valverde (D) http://orcid.org/0000-0002-9096-9274

Maria Castro (D) http://orcid.org/0000-0001-8941-5795 


\section{References}

Aguero-Valverde, J. (2011). Direct spatial correlation in crash frequency models. 3rd International Conference on Road Safety and Simulation Indianapolis, Indiana, USA.

Aguero-Valverde, J., \& Jovanis, P. (2008). Analysis of road crash frequency with spatial models. Transportation Research Record: Journal of the Transportation Research Board, 2061(1), 55-63. doi:10.3141/2061-07

Aguero-Valverde, J., \& Jovanis, P. P. (2006). Spatial analysis of fatal and injury crashes in Pennsylvania. Accident Analysis \& Prevention, 38(3), 618-625. doi:10.1016/j.aap.2005.12. 006

Aguero-Valverde, J., Wu, K. K., \& Donnell, E. T. (2016). A multivariate spatial crash frequency model for identifying sites with promise based on crash types. Accident Analysis \& Prevention, 87, 8-16. doi:10.1016/j.aap.2015.11.006

Berg, A., Meyer, R., \& Yu, J. (2004). Deviance information criterion for comparing stochastic volatility models. Journal of Business \& Economic Statistics, 22(1), 107-120. doi:10. 1198/073500103288619430

Besag, J., York, J., \& Molli $\square$, A. (1991). A Bayesian image restoration with two applications in spatial statistics. Annals of the Institute of Statistical Mathematics, 43(1), 1-59. Find this article online. doi:10.1007/BF00116466

Blangiardo, M., Cameletti, M., Baio, G., \& Rue, H. (2013). Spatial and spatio-temporal models with R-INLA. Spatial and Spatio-Temporal Epidemiology, 4, 33-49. doi:10.1016/j. sste.2012.12.001

Boulieri, A., Liverani, S., de Hoogh, K., \& Blangiardo, M. (2017). A space-time multivariate Bayesian model to analyse road traffic accidents by severity. Journal of the Royal Statistical Society: Series A (Statistics in Society), 180 (1), 119-139. doi:10.1111/rssa.12178

Chen, F., \& Chen, S. (2011). Injury severities of truck drivers in single- and multi-vehicles accidents on rural highways. Accident Analysis \& Prevention, 43(5), 1677-1688. doi:10. 1016/j.aap.2011.03.026

El-Basyouny, K., \& Sayed, T. (2009). Accident prediction models with random corridor parameters. Accident Analysis \& Prevention, 41(5), 1118-1123. doi:10.1016/j.aap.2009.06. 025

Geedipally, S. R., Lord, D., \& Dhavala, S. S. (2014). A caution about using Deviance Information Criterion while modelling traffic crashes. Safety Science, 62, 495-498. doi:10. 1016/j.ssci.2013.10.007

Gelman, A., Hwang, J., \& Vehtari, A. (2013). Understanding predictive information criteria for Bayesian models. Statistics and Computing, 24(6), 997-1016. doi:10.1007/s11222-0139416-2

Guo, Q., Xu, P., Pei, X., Wong, S. C., \& Yao, D. (2017). The effect of road network patterns on pedestrian safety: A zone-based Bayesian spatial modelling approach. Accident Analysis \& Prevention, 99(2017), 114-124. doi:10.1016/j.aap.2016.11.002

Hu, S., Ivan, J. N., Ravishanker, N., \& Mooradian, J. (2013). Temporal modeling of highway crash counts for senior and non-senior drivers. Accident Analysis \& Prevention, 50, 1003-1013. doi:10.1016/j.aap.2012.08.001

Huang, H., Zhou, H., Wang, J., Chang, F., \& Ma, M. (2017). A multivariate spatial model of crash frequency by transportation modes for urban intersections. Analytic Methods in Accident Research, 14(2017), 10-21. doi:10.1016/j.amar.2017.01.001

Huang, H., \& Abdel-Aty, M. (2010). Multilevel data and Bayesian analysis in traffic safety. Accident Analysis \& Prevention, 42(2010), 1556-1565. doi:10.1016/j.aap.2010.03.013 
Ivan, J. N., Wang, C., \& Bernardo, N. R. (2000). Explaining two-lane highway crash rates using land use and hourly exposure. Accident Analysis \& Prevention, 32(6), 787-795. doi: 10.1016/S0001-4575(99)00132-3

Jovanis, P. P., \& Chang, H. (1986). Modeling the relationship of accident to miles traveled. Transportation Research Record, 1068, 42-51.

Karlaftis, M. G., \& Golias, I. (2002). Effects of road geometry and traffic volumes on rural roadway accident rates. Accident Analysis \& Prevention, 34(3), 357-365. doi:10.1016/ S0001-4575(01)00033-1

Li, L., Zhu, L., \& Sui, D. Z. (2007). A GIS-based Bayesian approach for analyzing spatial-temporal patterns of intra-city motor vehicle crashes. Journal of Transport Geography, 15(4), 274-285. doi:10.1016/j.jtrangeo.2006.08.005

Lord, D., \& Mannering, F. (2010). The statistical analysis of crash-frequency data: A review and assessment of methodological alternatives. Transportation Research Part A: Policy and Practice, 44, 291-305. doi:10.1016/j.tra.2010.02.001

Ma, J., Kockelman, K. M., \& Damien, P. (2008). A multivariate Poisson-lognormal regression model for prediction of crash counts by severity, using Bayesian methods. Accident Analysis \& Prevention, 40(3), 964-975. doi:10.1016/j.aap.2007.11.002

Miaou, S., \& Lum, H. (1993). Statistical evaluation of the effects of highway geometric design on truck accident involvements. Transportation Research Record: Journal of the Transportation Research Board, 1407, 11-24.

Mitra, S. (2009). Spatial autocorrelation and Bayesian spatial statistical method for analyzing intersections prone to injury crashes. Transportation Research Record: Journal of the Transportation Research Board, 2136(1), 92-100. doi:10.3141/2136-11

Montella, A., Colantuoni, L., \& Lamberti, R. (2008). Crash prediction models for rural motorways. Transportation Research Record: Journal of the Transportation Research Board, 2083(1), 180-189. doi:10.3141/2083-21

Moore, D. N., Schneider, I. W.H., Savolainen, P. T., \& Farzaneh, M. (2011). Mixed logit analysis of bicyclist injury severity resulting from motor vehicle crashes at intersection and non-intersection locations. Accident Analysis \& Prevention, 43(3), 621-630. doi:10. 1016/j.aap.2010.09.015

Osama, A., \& Sayed, T. (2017). Evaluating the impact of socioeconomics, land use, built environment, and road facility on cyclist safety. Transportation Research Record: Journal of the Transportation Research Board, 2659(1), 33-42. doi:10.3141/2659-04

Plummer, M. (2008). Penalized loss functions for Bayesian model comparison. Biostatistics, 9(3), 523-539. doi:10.1093/biostatistics/kxm049

Pooley, C. M., \& Marion, G. (2018). Bayesian model evidence as a practical alternative to deviance information criterion. Royal Society Open Science, 5(3), 171519. doi:10.1098/ rsos. 171519

Pulugurtha, S. S., Duddu, V. R., \& Kotagiri, Y. (2013). Traffic analysis zone level crash estimation models based on land use characteristics. Accident Analysis \& Prevention, 50, 678-687. doi:10.1016/j.aap.2012.06.016

Qin, X., Ivan, J. N., \& Ravishanker, N. (2004). Selecting exposure measures in crash rate prediction for two-lane highway segments. Accident Analysis \& Prevention, 36(2), 183-191. doi:10.1016/S0001-4575(02)00148-3

Rue, H., \& Martino, S. (2007). Approximate Bayesian inference for hierarchical Gaussian Markov random field models. Journal of Statistical Planning and Inference, 137(10), 3177-3192. doi:10.1016/j.jspi.2006.07.016

Rue, H., Martino, S., \& Chopin, N. (2009). Approximate Bayesian inference for latent Gaussian models by using integrated nested Laplace approximations. Journal of the Royal 
Statistical Society: Series B (Statistical Methodology), 71(2), 319-392. doi:10.1111/j.14679868.2008.00700.x

Sauter, R., \& Held, L. (2015). Network meta-analysis with integrated Laplace approximations. Biometrical Journal, 57(6), 1038-1050. doi:10.1002/bimj.201400163

Serhiyenko, V., Ivan, J. N., Ravishanker, N., \& Islam, M. S. (2014). Dynamic compositional modeling of pedestrian crash counts on urban roads in Connecticut. Accident Analysis \& Prevention, 64, 78-85. doi:10.1016/j.aap.2013.11.006

Serhiyenko, V., Mamun, S. A., Ivan, J. N., \& Ravishanker, N. (2016). Fast Bayesian inference for modeling multivariate crash counts. Analytic Methods in Accident Research, 9, 44-53. doi:10.1016/j.amar.2016.02.002

Song, J. J., Ghosh, M., Miaou, S., \& Mallick, B. (2006). Bayesian multivariate spatial models for roadway traffic crash mapping. Journal of Multivariate Analysis, 97(1), 246-273. doi: 10.1016/j.jmva.2005.03.007

Spiegelhalter, D., Best, N., Carlin, B., \& Van Der Linde, A. (2002). Bayesian measures of model complexity and fit. Journal of the Royal Statistical Society: Series B (Statistical Methodology), 64(4), 583-639. doi:10.1111/1467-9868.00353

Spiegelhalter, D., Best, N., Carlin, B., \& Van Der Linde, A. (2014). The deviance information criteria: 12 years on. Journal of the Royal Statistical Society: Series B (Statistical Methodology), B76, 485-493. doi:10.1111/rssb.12062

Van Ravenzwaaij, D., Cassey, P., \& Brown, S.D. (2018). A simple introduction to Markov Chain Monte-Carlo sampling. Psychonomic Bulletin \& Review, 25(1), 143-154. doi:10. 3758/s13423-016-1015-8

Vogt, A., \& Bared, J. (1998). Accident models for two-lane rural segments and intersections. Transportation Research Record: Journal of the Transportation Research Board, 1635(1), 18-29. doi:10.3141/1635-03

Wang, K., Ivan, J. N., Ravishanker, N., \& Jackson, E. (2017). Multivariate Poisson lognormal modeling of crashes by type and severity on rural two lane highways. Accident Analysis \& Prevention, 99, 6-19. doi:10.1016/j.aap.2016.11.006

Washington, S. P., Karlaftis, M. G., \& Mannering, F. L. (2003). Statistical and econometric methods for transportation data analysis. London/Boca Raton, FL: Chapman \& Hall/ CRC.

World Health Organization. (2015). Global status report on road safety. Geneva (Switzerland): World Health Organization.

World Health Organization. (2018). Global status report on road safety. Geneva (Switzerland): World Health Organization. 